\title{
Problems in the Development of College Students' Tourism Market and Its Countermeasures*
}

\author{
Liguang Zhao \\ School of Taxation \\ Jilin University of Finance and Economics \\ Changchun, China 130117
}

\author{
Mingju Liu \\ Yatai School of Business Management \\ Jilin University of Finance and Economics \\ Changchun, China 130117
}

\author{
Hongxiang $\mathrm{Zi}$ \\ Yatai School of Business Management \\ Jilin University of Finance and Economics \\ Changchun, China 130117
}

\begin{abstract}
This article systematically summarizes the concepts and characteristics of the college student tourism market. Based on the analysis of the current situation of the college student tourism market, it summarizes the problems existing in the college student tourism market and proposes feasible countermeasures for the development of college student tourism.
\end{abstract}

Keywords—college student tourism; tourism market; market development; tourism enterprise

\section{INTRODUCTION}

College students, as a special group of people in the society, have high cultural quality and relatively abundant time. At the same time, they have a sense of freshness, curiosity, exploration spirit and pursuit of leisure life. College students have now become one of the most dynamic teams in the travel market. However, while the development potential of the university student tourism market is great, there are also various problems such as low development intensity, lack of pertinence, less publicity, less marketing activities, and less attention from all walks of life.

\section{RELATED CONCEPTS}

\section{A. The Concept of College Students' Tourism}

College student tourism refers to organized and orderly tourism activities conducted by college students during college. They use work-study programs, part-time jobs, and scholarships to earn money. They go out to travel while completing their studies, combining theory and practice to improve their education and increasing social experience. As a powerful team with potential and vitality, it has huge

*Fund: Social Science project of Jilin Province (2018B81); Project of Jilin Province Education Department in 2020: "Research on development path of rural tourism in Jilin Province under the background of territory tourism"; Jilin University of Finance and Economics 'counselor work excellent project "Study on the cultivation of students' ideals and beliefs from the perspective of internet public opinion". economic and social benefits, and the market prospect is very broad.

\section{B. Characteristics of College Student Tourism}

1) Pursuing economy and benefits, and paying more attention to the experience in the tourism process: College students can't be completely independent in their economics during college. They basically rely on parental support. So when they travel, they generally choose economical and affordable forms of tourism. The material requirements are not high during the travel process, as long as the food and housing are basically met. They pay more attention to spiritual enjoyment. They yearn for the natural ecology, history, and ethnic customs of a certain place, such as the exotic characteristics of the ethnic minorities in Lijiang, Dali. However, the travel products of current travel agencies and other travel companies are too ordinary, not fresh, and too boring. They really just travel for travel, get in the car to sleep, get out of the car to take pictures. In this way, the desire of college students to pursue individualization, specialization, and liberalization will not be satisfied. College students not only focus on the scenery of the destination, but also attach great importance to the experience during the trip.

2) Mainly for tourism purposes of sightseeing and leisure vacation: Due to limited funding for college students, the choice of accommodation, transportation and tourist destinations during travel is extremely limited. Most of their tours are based on short, half-way tourist sites. Today's sightseeing and tourism incorporates more cultural connotation and leisure vacation content, so choosing tourism to acquire more new knowledge and expand communication has a strong appeal to college students. Most of them think that feeling the nature of the original ecology can relax people. After an intense job or study, a walk-and-go trip can integrate yourself into nature and feel 
the charm of nature, which is also helpful for physical and mental health and cultivating sentiment.

3) Most of the travel methods are accompanied by classmates, friends, and lovers: The biggest pursuit of college students when traveling is that the feelings in the tourism process can meet their individual needs. Travel routes arranged by travel agencies are easily bound in both time and space, and they cannot exert lively and healthy energy in the process of travel. Therefore, they are more willing to go with their classmates, friends, or lovers. This choice allows them to do whatever they want in the process of traveling, and it can also enhance each other's emotions. Furthermore, college students are becoming more independent and self-aware. They can take advantage of their classmates, fellow citizens, and friends all over the country to arrange their own travel routes.

4) The continuous development of the Internet has made the herd mentality of college students remarkable: The world today is an information age. Moreover, for college students living in groups, not only the tourism market is concentrated, but the speed at which tourism information resources are spread is even more alarming. And college students are not mature enough, they are more impulsive and are more susceptible to the surrounding environment. There is not enough preliminary preparation when making travel decisions, so college students are a little hesitant in their thinking, and they are susceptible to the hints of classmates and friends in their actions. They blindly follow the opinions of others and follow the trend, they have a significant herd mentality. These will lead to the situation of collective tourism.

5) Travel time of college students is more concentrated: With the reform of the national vacation system, the Qingming Festival, the Dragon Boat Festival and the MidAutumn Festival have been added, as well as the Spring Festival, May Day, and Eleven, which have always led to more and more holidays. For college students, there are two long vacations in winter and summer. According to statistics, college students have a holiday of nearly 170 days a year. Although there is a lot of leisure time, the time for college students to travel is very concentrated. Most students go out to travel during the winter and summer vacations because the winter and summer vacations are long, so they can fully arrange their own itineraries, and the content of travel is more abundant.

\section{The CURRENT Status OF THE COLLEGE StUdENT TRAVEL MARKET}

\section{A. Attitude and Motivation for Tourism}

Travelers' attitudes and behaviors also have a great relationship. The attitude of tourism determines the decision of tourism, which restricts the implementation of tourism behavior. College students have to go through intense psychological struggles and need to consider issues such as time, place, and funding. Studies show that college students from places with lower levels of economic development are less enthusiastic about tourism, but they have a positive attitude towards the overall situation of outbound tourism. Tourism motivation refers to the driving force for a person to decide to travel in order to meet some of his needs, which is a psychological motivation to motivate a person to travel and what kind of travel. There is a need for tourism before generating tourism motivation. The travel needs of college students are to alleviate the pressure of study and life, appreciate the scenic spots, cultural relics, etc., to pursue psychological relaxation, as well as adventure study, increase knowledge, and make friends.

\section{B. College Students' Travel Preferences}

1) Preference for tourist attractions: The areas most desired by college students are mainly Jiangnan towns in Jiangsu, Zhejiang, and Shanghai, ethnic minority areas in Yunnan, northeast snowy areas, Hainan beaches, and desert exploration and rock climbing. They prefer natural scenery, historical monuments, leisure vacations, ethnic customs, red tourism and exciting tourism.

2) Preference for "food": College students have low dietary requirements, as long as they are clean, nutritious, and affordable. Locally flavored snacks are often the most tempting for them. If food can be stored for a long time, they are also happy to buy it.

3) Preference for "accommodation": College students choose youth hostels, homestays and some budget hotels, as long as they are safe, clean and comfortable. Due to economic constraints, very few students live in luxury hotels. Living in Youth Hostel can meet like-minded friends, which is also very attractive to them.

4) Preference for "traffic": According to the survey, college students choose more trains, buses, and longdistance buses when they travel, and rarely choose planes and taxis. They do not have too many requirements for the choice of transportation, but they are pursuing strangeness and different. For example, cycling to Tibet or some Southeast Asian countries is very attractive to them.

\section{The Proportion of Travel Is Increasing Year by Year}

College students are a group of people with knowledge, culture, curiosity and a strong sense of foresight. Young and energetic, they are curious about all unknown things. They are eager to get what they can't learn in school by traveling. First of all, through tourism, they can understand the society, experience the national customs, customs and lifestyles of the country and even the world, and increase their knowledge and broaden their horizons. Secondly, college students have a lot of stress during the class, and there are usually many events such as community activities and competitions. Traveling out can relieve stress and relax your tension. According to an online survey, nearly $70 \%$ of students expressed the hope that they can travel more during college to see the outside world. Among them, students who particularly like to travel account for as much as $20 \%$ or more, and the general preference is about $50 \%$. From this, it can be seen that the number of college students going abroad 
has increased year by year, and they have a positive attitude towards tourism, and the potential for market development is huge.

\section{Travel Time}

Compared with middle school, college students have a relaxed curriculum, no vacation homework, and more leisure time, in addition, there are holidays such as May 1st and 11th National Day and winter and summer vacations, which provide necessary conditions for outings. Therefore, college students have more time to travel and have a high degree of freedom in travel arrangements.

\section{PRoblems IN THE COLlege StUdent TRAVEL MARKET}

\section{A. The Concept of Tourism Consumption}

During the survey on the concept of consumption, it was found that a small number of students said that they could accept traveling by borrowing money or loans. Most students feel that they should do what they can, consume rationally, and cannot develop a bad habit of borrowing money. This shows that most students still keep rational consumption. However, due to different consumer concepts, some students are unwilling to travel even if they have money. These students feel that it is better to use the money for shopping, school supplies, clothes, etc. The tour is invisible and inaccessible, and the money is spent on wheels and tickets and accommodation. And some people think that going out to travel can be seen, to see the different customs, and relax, it is a very meaningful thing. They have a strong desire to travel and want to go out whenever they have the chance.

\section{B. Overpriced Products and Lack of Personalized Travel Products}

At present, college students do not have a stable income and are a disadvantaged group in terms of tourism expenditure. Therefore, when faced with tourism products, they are the most price-sensitive, and the second is how attractive fun is to them. The tourism products on the market are generally formulated for groups with a certain income. In order to make money, some merchants set prices many times higher than in the market. Such consumption college students can't afford it at the university stage, so the tourism market for college students is sluggish.

\section{The Problem of Tourism Safety for College Students Is Prominent}

In recent years, every time a long vacation or a small vacation, almost all kinds of safety problems encountered by college students in the travel process will be reported. There are various types of people who are trapped on the mountain while climbing, are washed away by the waves, and have car accidents. The consequences are minor injuries and severe deaths. The occurrence of these accidents will undoubtedly bring a heavy blow to families. The tourism safety of college students has been widely concerned by the society, and the causes of college students' tourism safety issues have also been analyzed. For example, the undergraduates' awareness of travel safety is weak, lack of self-protection awareness and knowledge of travel safety, school safety education is not enough, and infrastructure in tourist attractions has security loopholes and other reasons.

\section{Outdated Tourism Marketing Methods, Single Content and Great Appeal}

At present, tourism companies still go to school to propagate through traditional methods such as leaflets and posters. The marketing methods are outdated and the content is single. The content displayed is limited to simple travel itineraries and pictures. Many college students will think this is false, and the effect is not very satisfactory. There is relatively much content on the Internet. Students can compare prices, read reviews, etc., and get a wealth of information. However, the information on the Internet is too huge, and there is no such keyword as "big college students" in the travel route information, so it is difficult for college students to find products suitable for them. Many tourism companies attract college students at low prices, but they cannot guarantee the quality and there are tourism scams. Therefore, college students generally have lower trust in tourism companies.

\section{E. Inadequate Attention from Tourism-related Departments}

As the safety of college students' travel is not guaranteed, accidents are easy to occur. Therefore, the school has a nonsupportive, non-opposed, and unorganized attitude towards the collective travel of college students, and is afraid to take responsibility for accidents, but does not consider the many benefits of college student travel. In addition, undergraduates have a long history of low spending power and are constrained by ideology. Many tourism companies have not realized that the potential of college students 'tourism is great. China has implemented too few preferential policies for college student travel. Only college and secondary school students can purchase discounted train tickets four times a year, and it is limited to families and schools. The state maintains a conservative attitude towards university student outings, and without government policy support, companies cannot afford to be bold in the college student travel market.

\section{COUNTERMEASURES FOR THE DEVELOPMENT OF COLLEGE STUDENT TOURISM MARKET}

\section{A. Guiding College Students to Form a Correct Concept of Tourism Consumption}

In college, tourism should not become luxury consumption. Students should correct the bad comparison style, consume rationally, and promote diligence and thrift. They must act within their means, not too unexpectedly. They should pay more attention to the scenery along the way, increase their knowledge, release their mood, relieve their stress, exercise their bodies, cultivate their independence, and advocate green tourism and civilized tourism. 


\section{B. Increasing Efforts to Develop Targeted College Student Tourism Lines}

Today's college students are pursuing personality, exciting and fresh things. To meet these needs, travel is the best way. College students travel not only to satisfy curiosity, but also driven by curiosity, so they often get the support of schools and parents. Therefore, the development of the college students market has great potential. People should start from the actual needs of college students, design the tourism special line needed by college students, and do what they like to develop a tourism product portfolio suitable for college students. Such as creative tourism, sports tourism, outdoor adventure, tourist couples tour and ladybro tour.

\section{Establishing and Improving Tourism Laws and Regulations to Ensure Safety}

First, countries have developed Tourism Law, but due to the introduction of a few years, is not yet mature, there are still many loopholes, so the state should improve tourism laws and regulations as soon as possible, so that tourists and business law, there is a security.

Secondly, schools should provide tourism safety education courses to guide students to travel safely. The school must not only provide tourism safety courses, but also innovate in content and form. Traditional safety knowledge is generally provided through lectures, bulletins, publicity, etc. This approach is too common to play a key role. Schools should pay attention to scenario design and involve students in the experience, just like fire drills to escape. This method is very impressive and the most direct and effective.

Finally, college students should strengthen their awareness of travel safety and learn about travel safety. College students should take the initiative to learn about travel safety through Internet, lectures, etc., to master the methods of first aid and prevent accidents, to enhance selfrescue ability and ability to handle emergencies. College students should make full preparations before going on a tour, and have a comprehensive understanding of the cities and scenic spots they go to, and travel companies.

\section{Exploring the Market Through Innovative Marketing}

1) Cultivating a large number of student campus agents: People with a lot of friends, wide information, and cheerfulness, especially students in tourism majors, are selected as tourism promotion and direct sales personnel. Putting aside university students' distrust in tourism companies, they can be hired as tour guides so that companies can communicate with students face to face and take root in the college student tourism market.

2) Creating a college student travel brand to increase visibility: College students have a trust in the brand, and their loyalty to the brand is stronger than the general population. Enterprises should spread their tourism culture on campus while building their brand. The combination of brand and culture can produce good results. People with significant influence in tourism can be invited to give lectures to university students, and at the same time, they can also publicize the company's own image.

3) Integration network with campus media: People can make use of the characteristics of students like to play WeChat, Weibo, QQ, Tik Tok, Baidu Tieba and so on, and at the same time, publicize on campus posters, boards, banners and other places. People can also set up fixed marketing points in places where colleges and universities are concentrated, which is conducive for students to find counseling points when they have problems, and increase students' trust in tourism companies.

4) Tourism enterprises can be associated with college associations or colleges: At present, colleges and universities across the country have a variety of societies, with wide coverage and fast information dissemination. In particular, some universities have established tourism associations. This association is closely related to tourism. Each year, a tour guide competition is held and sponsorship is needed. Enterprises can use this opportunity to sponsor communities, promote themselves, promote tourism products, and develop the tourism market.

\section{E. Strengthening the Attention of Government Departments and Schools and Tourism Enterprises}

1) Government departments should strengthen the guidance of college student tourism: Doing well in the university student tourism market needs all-round cooperation from the government, schools, and enterprises. The government should also give play to the government's functions, provide policy support, actively guide college students to travel, and establish and improve laws and regulations, establish corresponding tourism safety agencies, improve tourism insurance, strengthen tourism safety education, and increase college students' awareness of tourism safety. They need to strengthen the construction of infrastructure, provide preferential policies for college students, give preferential treatment in transportation, accommodation, catering, etc., and give certain subsidies to companies that do college student tourism.

2) Schools should guide college students to participate in tourism activities: Schools should train college students to have a correct outlook on tourism. On the whole, the advantages of outbound tourism for college students outweigh the disadvantages, and we should give certain affirmation. Schools should actively carry out safety education activities and establish a sense of tourism safety for college students. Colleges and universities should cultivate the all-round development of college students, take college student tourism as a favorable factor for the development of quality education, encourage college students to set up tour guide associations, tourism associations and other associations, and support college students in organizing outing tourism learning activities.

3) Tourism companies should actively develop the tourist market for college students: Tourism enterprises 
should pay full attention to college student tourists, comprehensively improve the level of tourism services, and meet the needs of college students to the greatest extent. The service to college students should be differentiated from other tourists, and tourism companies should give more concessions and concerns, attract repeat customers, and implement small profits but quick turnover marketing method.

\section{CONCLUSION}

The development potential of the college student tourism market is huge. Doing well in the university student tourism market requires not only the full cooperation of the government, schools and enterprises, but also guiding university students to form the correct concept of tourism consumption, intensifying efforts to develop targeted college student tourism special lines, establishing and improving tourism laws and regulations, and ensuring safety to open up the market through innovative marketing.

\section{REFERENCES}

[1] Lin Deqin, Yu Hui, Qiu Haihui. Research and Analysis on Tourism Behavior of College Students - Taking Fujian Jiangxia University as an Example [J]. Business Economy, 2019 (05): 172-175 + 182. (in Chinese)

[2] Liu Tianyue, Wang Junru. SWOT Analysis of Tourism Marketing Environment of College Students of Sanya [J]. Management and Administration, 2019 (10): 141-143. (in Chinese)

[3] Wang Xiong, Wu Min. On the Tourism Market of College Students in Anhui [J]. Education Forum, 2019 (14): 105-106. (in Chinese)

[4] Sun Jing. Research on the Development of Tourism Market for College Students in Huai'an [J]. Tourism Overview (Second Volume), 2019 (01): 27-28. (in Chinese)

[5] Pan Changhong. Research on the Development of College Students' Tourism Tourism Market [J]. Vacation Tour, 2018 (09): 23-27. (in Chinese)

[6] Zeng Lanfang, Wang Weijiang, Zhou Zefang, Chen Yifei. Analysis of the status quo of college student tourism and suggestions for the development of self-help tourism platforms [J]. Rural Economy and Science, 2018, 29 (13): 117-119. (in Chinese)

[7] Liao Kang, Yang Jianchang. Development of College Students' Tourism Market Based on Tourism Behavior Analysis [J]. Tourism Overview (Second Volume), 2018 (06): 22. (in Chinese)

[8] Lu Hengqin, Wang Kexin. Investigation and Research on College Students' Online Travel Information Search Behavior - Taking Wuxi City as an Example [J]. Northern Economy and Trade, 2018 (05): 154-155 + 158. (in Chinese) 